\title{
Controlled Synthesis of Polyepichlorohydrin with Pendant Cyclic Carbonate Functions for Isocyanate-Free Polyurethane Networks
}

\author{
ANNE-LAURE BROCAS, ${ }^{1}$ GABRIEL CENDEJAS, ${ }^{1}$ SYLVAIN CAILLOL, ${ }^{2}$ ALAIN DEFFIEUX, ${ }^{1}$ STEPHANE CARLOTTI ${ }^{1}$ \\ ${ }^{1}$ Université de Bordeaux, Laboratoire de Chimie des Polymères Organiques, CNRS, ENSCBP, 16 avenue Pey Berland, \\ 33607 Pessac Cedex, France \\ ${ }^{2}$ Institut Charles Gerhardt, UMR5253 CNRS/UM2/ENSCM/UM1, Ecole Nationale Supérieure de Chimie de Montpellier, \\ 8 rue de I'Ecole Normale, 34296 Montpellier Cedex 5, France
}

Received 2 February 2011; accepted 1 April 2011

DOI: 10.1002/pola.24699

Published online 27 April 2011 in Wiley Online Library (wileyonlinelibrary.com).

\begin{abstract}
Poly(allyl glycidyl ether) and poly(allyl glycidyl etherco-epichlorohydrin) were prepared by monomer-activated anionic polymerization. Quantitative and controlled polymerization of allyl glycidyl ether (AGE) giving high molar mass polyether was achieved in a few hours at room temperature in toluene using tetraoctylammonium salt as initiator in presence of an excess of triisobutylaluminum $\left(\left[i-\mathrm{Bu}_{3} \mathrm{Al}\right] /\left[\mathrm{NOct}_{4} \mathrm{Br}\right]=2-4\right)$. Following the same polymerization route, the copolymerization of AGE and epichlorohydrin yields in a living-like manner gradient-type copolymers with controlled molar masses. Chemical
\end{abstract}

modification of the pendant allyl group into cyclic carbonate was then investigated and the corresponding polymers were used as precursors for the isocyanate-free synthesis of polyurethane networks in presence of a diamine. Formation of crosslinked materials was followed and characterized by infrared and differential scanning calorimetry. (c) 2011 Wiley Periodicals, Inc. J Polym Sci Part A: Polym Chem 49: 2677-2684, 2011

KEYWORDS: anionic polymerization; isocyanate-free; monomer activation; polyepichlorohydrin; polyethers; polyurethanes
INTRODUCTION Polyurethanes materials, thanks to their versatile properties, are found in many applications in everyday life. ${ }^{1}$ They are most generally prepared from the reaction of polyols with isocyanates. ${ }^{2}$ However, today researches are more and more focused on a friendly environmental chemistry. ${ }^{3,4}$ One motivation deals with the development of an isocyanate-free route to polyurethanes that would prevent the use of isocyanates and therefore of highly toxic phosgene involved in their synthesis. A second motivation concerns the decrease of fossil feedstock and the use of natural products $^{5}$ as renewable raw chemicals. Among them, vegetable oils constitute an important feedstock already used for the synthesis of biodiesel and as a source of green chemicals. ${ }^{6-9}$ Glycerol, a byproduct of both the biodiesel production and the saponification of animal fats is obtained in large amount $(400,000$ tons in 2005) and needs to be better valorized as raw material. Their transformations into glycerol carbonate, aldehydes, ketones, and carboxylic acids, ${ }^{10}$ as well as epichlorohydrin $^{11}$ (ECH) and allyl glycidyl ether ${ }^{12}$ (AGE), were reported. Production of ECH from glycerol via dichlorination and deshydrochlorination has been recently industrialized. $^{13,14}$ AGE can be synthesized by the reaction of ECH with allyl alcohol, ${ }^{12}$ the latter being obtained by heating glycerol in presence of formic acid. ECH and AGE possess two functional groups, which make these monomers of interest for the preparation of reactive polymers even if the first one is toxic. Polyepichlorohydrin (PECH) can be readily modified by chemical substitution of the chloride atoms to yield a broad series of functional side chain polymers ${ }^{15,16}$ and more particularly to the synthesis of poly(glycidyl azide) used as precursor for energetic polyurethanes in the field of propellants. $^{17}$

In the same way, pendant allylic unsaturation of poly(allyl glycidyl ether) (PAGE) allows introducing various functions via the thiol-ene chemistry, ${ }^{18-21}$ as well as epoxide side groups by oxidation of the double bond. ${ }^{22}$ This latter group has a great chemical interest as it can be easily transformed into cyclic carbonate by reaction with carbon dioxide $\left(\mathrm{CO}_{2}\right){ }^{23}$

Beside polyethers with polymodal molar mass distribution that can be obtained by coordinated polymerization mechanisms, low to medium molar mass PECH and PAGE can be prepared by cationic (most preferably via the monomer activated mechanism), and/or by conventional anionic ringopening polymerizations. ${ }^{24,25}$ Indeed, the anionic polymerization of AGE, and more generally of alkylene oxides, suffers from chain transfer to monomer, which drastically limits the control of the polymerization. For AGE, best polymerization results were obtained with a suspension of potassium hydride 
and 18-crown- $6^{26}$ in tetrahydrofuran (THF), potassium hydride in association with benzyl alcohol, ${ }^{20}$ or potassium 3phenyl-1-propanolate. ${ }^{24}$ These systems exhibit a relatively good activity at 25 or $100{ }^{\circ} \mathrm{C}$ but obtained PAGEs possess molar masses lower than $10,000 \mathrm{~g} \mathrm{~mol}^{-1}$. Because of the nucleophilic attack of chloride by the alkoxide chain end in ECH anionic polymerization, PECH could not be prepared by conventional anionic polymerization. This is only recently that controlled polymerization of ECH could be achieved by anionic-activated monomer polymerization, using a combination of tetraalkylammonium salts and trialkylaluminum as initiator, thanks to the very low basicity of the propagating centers involved in this mechanism. ${ }^{27}$ This approach was applied in this study to the polymerization of AGE and to its statistical copolymerization with ECH, the latter monomer being also a model of numerous epoxides.

The chemical modification of the pendant allyl groups into cyclic carbonates by reaction with a peracide and $\mathrm{CO}_{2}$ was then investigated. Indeed, the reaction of oxiranes with $\mathrm{CO}_{2}$ to afford five-membered cyclic carbonates was reported to proceed in mild conditions in high yield..$^{23,28-30}$ The reaction of cyclic carbonate with amines to produce polyurethanes was also documented in literature. Bifunctional five-membered cyclic carbonates and various alkyl amines were used to synthesize linear polyhydroxyurethanes without the use of isocyanate. $^{31-36}$ By the same way, Wilkes ${ }^{37}$ and Petrovic ${ }^{38}$ synthesized polyurethanes starting from epoxidized soybean oil reacted with $\mathrm{CO}_{2}$ and then with diamines. As reported by Keul and Höcker, such materials can also be prepared by cationic ring-opening polymerization of trimethylene urethane ${ }^{39,40}$ or by reaction of activated carbonates with $\alpha, \omega$-diamines. ${ }^{41}$

In the last part of this work, the chemically modified PAGE and poly(allyl glycidyl ether-co-epichlorohydrin) [P(AGE-coECH)] bearing cyclic carbonate groups were investigated as precursors for the synthesis of polyurethane networks in presence of a diamine.

\section{EXPERIMENTAL}

\section{Materials}

ECH (99\%, Sigma Aldrich) and AGE (>99\%, TCI) were purified over $\mathrm{CaH}_{2}$ and distilled and stored under vacuum at room temperature in graduated glass tubes until use. Triisobutylaluminum $\left(i-\mathrm{Bu}_{3} \mathrm{Al}\right)\left(1 \mathrm{~mol} \mathrm{~L}^{-1}\right.$ in toluene, Aldrich) was used without further purification. Toluene (98\%, J.T. Baker) was purified with polystyryllithium seeds, distilled under vacuum and then stored in graduated glass tubes. Tetraoctylammonium bromide (NOct ${ }_{4} \mathrm{Br}, 98 \%$, Aldrich) was solubilized into dried toluene in calibrated glass tubes fitted with PTFE stopcocks. m-chloroperoxybenzoic acid (mCPBA, $\leq 77 \%$ ) and lithium bromide (LiBr, 99+\%), were purchased from Aldrich and used without further purification. Isophorone diamine (IPDA, 99+\%) was purchased from Acros Organics. $\mathrm{CO}_{2}$ was purchased from Air Liquide.

\section{Procedures}

All (co)polymerizations were carried out at $25{ }^{\circ} \mathrm{C}$ under argon in a glass reactor equipped with a magnetic stirrer and fitted with Teflon stopcocks. As example, a polymerization reactor was flamed under vacuum and cooled down prior introduction of $6 \mathrm{~mL}$ of toluene, $0.80 \mathrm{~mL}$ of AGE ( $6.74 \mathrm{mmol}$ ), and $0.65 \mathrm{~mL}$ of ECH (8.31 mmol) through connected glass tubes. Then, $0.70 \mathrm{~mL}(0.15 \mathrm{mmol})$ of a toluene solution of $\mathrm{NOct}_{4} \mathrm{Br}(C=$ $0.22 \mathrm{M})$ followed by $0.31 \mathrm{~mL}(0.31 \mathrm{mmol})$ of $i$ - $\mathrm{Bu}_{3} \mathrm{Al}$ solution in toluene $(C=1 \mathrm{M})$ were added via a syringe under argon. The polymerization was allowed to proceed at $-30{ }^{\circ} \mathrm{C}$ for the initiation and at $25{ }^{\circ} \mathrm{C}$ for $1 \mathrm{~h}$. A small amount of ethanol was then added to stop the reaction. The polymer conversion was determined gravimetrically (100\%) after complete drying of the polymer under vacuum, at $50{ }^{\circ} \mathrm{C} . \overline{M_{\mathrm{n}}}$ Size exclusion chromatography $(\mathrm{SEC})=15,000 \mathrm{~g} \mathrm{~mol}^{-1}, I_{\mathrm{p}}=1.09$.

${ }^{1} \mathrm{H}$ NMR of P(AGE-Co-ECH): $-\mathrm{O}-\mathrm{CH}_{2}(1)-\mathrm{CH}(2)\left[\mathrm{CH}_{2}(3)-\mathrm{O}-\right.$ $\left.\mathrm{CH}_{2}(4)-\mathrm{CH}(5)-\mathrm{CH}_{2}(6)\right]-\mathrm{CO}-\mathrm{O}-\mathrm{CH}_{2}(7)-\mathrm{CH}(8)\left[\mathrm{CH}_{2}(9)-\mathrm{Cl}\right]: 1$, $2,3,7,8,9$, multiplet at 3.33-3.67 ppm; 4, doublet at 3.98 ppm; 5, $5.87 \mathrm{ppm}(1 \mathrm{H}) ; 6,5.15-5.27 \mathrm{ppm}(2 \mathrm{H}) .{ }^{13} \mathrm{C}$ NMR of P(AGE-co-ECH): $\quad-\mathrm{O}-\mathrm{CH}_{2}(1)-\mathrm{CH}(2)\left[\mathrm{CH}_{2}(3)-\mathrm{O}-\mathrm{CH}_{2}(4)\right.$ $\left.-\mathrm{CH}(5)-\mathrm{CH}_{2}(6)\right]-\mathrm{CO}-\mathrm{O}-\mathrm{CH}_{2}(7)-\mathrm{CH}(8)\left[\mathrm{CH}_{2}(9)-\mathrm{Cl}\right]: 1,3$, 4, 7, 8, 70-72 ppm; 2, 79.14 ppm; 5, 135.4 ppm; 6, 117.01 ppm; 9, 43.99 ppm.

\section{Epoxidation of AGE Units}

A typical epoxidation reaction of the allyl groups of $\mathrm{P}(\mathrm{AGE}-$ co-ECH) was carried out in dichloromethane with 2.5 molar excess of $m$ CPBA. The reaction mixture was stirred for $8 \mathrm{~h}$ at room temperature. Then the solution was washed three times with a $\mathrm{NaHCO}_{3}$ solution and dried for 1 night under vacuum.

${ }^{1} \mathrm{H}$ NMR of an epoxidized P(AGE-Co-ECH): $-\mathrm{O}-\mathrm{CH}_{2}(1)$ $-\mathrm{CH}(2)\left[\mathrm{CH}_{2}(3)-\mathrm{O}-\mathrm{CH}_{2}(4)-\mathrm{CH}(5)-\mathrm{O}-\mathrm{CH}_{2}(6)\right]-\mathrm{CO}-\mathrm{O}-$ $\mathrm{CH}_{2}(7)-\mathrm{CH}(8)\left[\mathrm{CH}_{2}(9)-\mathrm{Cl}\right]: 1,2,3,4,7,8,9,3.13-3.76$ ppm; 5, $2.98 \mathrm{ppm}(1 \mathrm{H}) ; 6,2.43$, and $2.62 \mathrm{ppm}(2 \mathrm{H}) .{ }^{13} \mathrm{C}$ NMR of an epoxidized P(AGE-Co-ECH): $-\mathrm{O}-\mathrm{CH}_{2}(1)$ $-\mathrm{CH}(2)\left[\mathrm{CH}_{2}(3)-\mathrm{O}-\mathrm{CH}_{2}(4)-\mathrm{CH}(5)-\mathrm{CH}_{2}(6)\right]-\mathrm{CO}-\mathrm{O}-\mathrm{CH}_{2}(7)-$ $\mathrm{CH}(8)\left[\mathrm{CH}_{2}(9)-\mathrm{Cl}\right]: 1,3,4,7,8,70-72 \mathrm{ppm} ; 2,79.37 \mathrm{ppm}$; 5, 59.42 ppm; 6, 43.75 ppm; 9, 43.75 ppm.

\section{Carbonatation Reaction}

One gram of an epoxidized P(AGE-Co-ECH) (4.38 mmol of epoxide groups) and $19 \mathrm{mg}$ of $\operatorname{LiBr}(0.22 \mathrm{mmol})$ were dissolved in $15 \mathrm{~mL}$ of dimethylformamide (DMF). The solution was introduced into a reactor and the atmosphere was replaced with $\mathrm{CO}_{2}(P=1$ bar $)$. The solution was then allowed to stand at $80{ }^{\circ} \mathrm{C}$ with continuous stirring during 12 h. The solution was dried under vacuum at $70{ }^{\circ} \mathrm{C}$.

${ }^{1} \mathrm{H} \quad \mathrm{NMR}$ of carbonated P(AGE-co-ECH): $-\mathrm{O}-\mathrm{CH}_{2}(1)$ $-\mathrm{CH}(2)\left[\mathrm{CH}_{2}(3)-\mathrm{O}-\mathrm{CH}_{2}(4)-\mathrm{CH}(5)-\mathrm{O}-\mathrm{CO}-\mathrm{O}-\mathrm{CH}_{2}(6)\right]-$ Co-O- $\mathrm{CH}_{2}(7)-\mathrm{CH}(8)\left[\mathrm{CH}_{2}(9)-\mathrm{Cl}\right]: 1,2,3,4,7,8,9,3.42-$ 3.98 ppm; 5, 4.83 ppm $(1 \mathrm{H}) ; 6,4.39-4.50 \mathrm{ppm}(2 \mathrm{H}) .{ }^{13} \mathrm{C}$ NMR of carbonated P(AGE- $\mathrm{CO}-\mathrm{ECH}):-\mathrm{O}-\mathrm{CH}_{2}(1)-\mathrm{CH}(2)$ $\left[\mathrm{CH}_{2}(3)-\mathrm{O}-\mathrm{CH}_{2}(4)-\mathrm{CH}(5)-\mathrm{O}-\mathrm{C}\left(5^{\prime}\right) \mathrm{O}-\mathrm{O}-\mathrm{CH}_{2}(6)\right]-\mathrm{CO}-\mathrm{O}-$ $\mathrm{CH}_{2}(7)-\mathrm{CH}(8)\left[\mathrm{CH}_{2}(9)-\mathrm{Cl}\right]: 1,3,4,5,7,8,69-72 \mathrm{ppm} ; 2$, 79.37 ppm; 5', 155.32 ppm; 6, 66.44 ppm; 9, 43.99 ppm.

\section{Polyurethane Synthesis}

$0.5 \mathrm{~g}$ of carbonated copolymers and IPDA were stirred at $80{ }^{\circ} \mathrm{C}$ for $2 \mathrm{~h}$. IPDA was used in stoichiometric molar amount with respect to the number of epoxide groups. 
TABLE 1 Polymerization of Allyl Glycidyl Ether initiated by $\mathrm{NOct}_{4} \mathrm{Br} / i-\mathrm{Bu}_{3} \mathrm{Al}$

\begin{tabular}{|c|c|c|c|c|c|c|c|}
\hline Run & {$\left[i-\mathrm{Bu}_{3} \mathrm{Al}\right] /\left[\mathrm{NOct}_{4} \mathrm{Br}\right]$} & Time $(\mathrm{h})$ & $\bar{M}_{\mathrm{nth}}{ }^{\mathrm{b}}\left(\mathrm{g} \mathrm{mol}^{-1}\right)$ & $\overline{M_{\mathrm{nexp}}}(\mathrm{RI})^{\mathrm{c}}\left(\mathrm{g} \mathrm{mol}^{-1}\right)$ & $\frac{\overline{M_{w}}}{\overline{M_{n}}}$ & $\overline{M_{\text {nexp }}}(\operatorname{Visco})^{\mathrm{d}}\left(\mathrm{g} \mathrm{mol}^{-1}\right)$ & $\frac{\overline{M_{\mathrm{w}}}}{\overline{\bar{M}_{\mathrm{n}}}}$ \\
\hline 1 & 2 & 1.5 & 5,000 & 6,900 & 1.08 & nd & nd \\
\hline 2 & 2 & 1.5 & 10,000 & 14,500 & 1.07 & nd & nd \\
\hline 3 & 2 & 1.5 & 20,000 & 30,000 & 1.05 & 21,000 & 1.09 \\
\hline 4 & 2 & 1.5 & 50,000 & 70,000 & 1.22 & 46,000 & 1.24 \\
\hline 5 & 3 & 2 & 75,000 & 72,000 & 1.40 & 60,000 & 1.37 \\
\hline 6 & 4 & 4 & 100,000 & 109,000 & 1.32 & 70,000 & 1.35 \\
\hline
\end{tabular}

Toluene, $20{ }^{\circ} \mathrm{C}$, $[\mathrm{AGE}]=1.5 \mathrm{~mol} \mathrm{~L}^{-1}$, conversion ${ }^{\mathrm{a}}$ : $100 \%$.

a Determined gravimetrically.

b $\bar{M}_{\mathrm{n}}$ th $=[\mathrm{AGE}]_{0} /\left[\mathrm{NOc}_{4} \mathrm{Br}\right] \times M_{\mathrm{AGE}} \times$ yield .

${ }^{c}$ Number-average molar mass determined by size exclusion chromatography in tetrahydrofuran using a calibration with polystyrene standards.

\section{Analysis}

Polymer molar masses were determined by SEC at $40{ }^{\circ} \mathrm{C}$ using THF as eluent. Measurements in THF were performed on a PL GPC50 integrated system with RI, UV, and viscometer detectors and three TSK columns: G4000HXL (particles of $5 \mu \mathrm{m}$, pore size of $200 \AA$, and exclusion limit of 400,000 Da), G3000HXL (particles of $5 \mu \mathrm{m}$, pore size of $75 \AA$, and exclusion limit of 60,000 Da), G2000HXL (particles of $5 \mu \mathrm{m}$, pore size of $20 \AA$, and exclusion limit of $10,000 \mathrm{Da}$ ) at THF

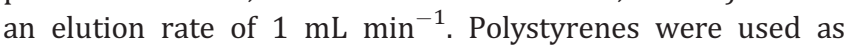
standards.

${ }^{1} \mathrm{H}$ and ${ }^{13} \mathrm{C}$ NMR (400 MHz) analysis of the polymers and copolymers were performed on a Brüker Avance 400 spectrometer in $\mathrm{CDCl}_{3}$ at room temperature.

FTIR (transmission mode) spectra were obtained using a Brüker Tensor 27 spectrometer.

Differential scanning calorimetry (DSC) measurements were carried out on a DSC Q100 apparatus from TA Instruments. Polyurethane samples were heated from -90 to $220{ }^{\circ} \mathrm{C}$ at a rate of $5{ }^{\circ} \mathrm{C} \min ^{-1}$. Consecutive cooling and second heating runs were performed at $10{ }^{\circ} \mathrm{C} \mathrm{min}^{-1}$.

\section{RESULTS AND DISCUSSION}

\section{Controlled Synthesis of Poly(allyl glycidyl ether)}

The polymerization of AGE was performed using the monomer-activated anionic polymerization approach that was already applied for various other epoxide monomers. ${ }^{27,42-46}$ This polymerization process requires the use of an organic salt as initiator (typically $\mathrm{NOct}_{4} \mathrm{Br}$ ) in association with an organometallic Lewis acid activator (triisobutylaluminum) present in slight molar excess with respect to the initiator. In the case of AGE, the polymerization was initiated at $-30{ }^{\circ} \mathrm{C}$ to reduce the initial polymerization rate and to prevent side reactions, ${ }^{43}$ then the reaction medium was allowed to rise up to room temperature. Some polymerization results are collected in Table 1. Depending on the targeted PAGE molar mass and to achieve quantitative polymerization, initial [i$\left.\mathrm{Bu}_{3} \mathrm{Al}\right] /\left[\mathrm{NOct}_{4} \mathrm{Br}\right]$ ratio ranging from 2 to 4 were used. At ratio 4, PAGE with an absolute molar mass equal to $70,000 \mathrm{~g}$
${ }^{d}$ Number-average molar mass determined by size exclusion chromatography equipped with a viscometer detector in tetrahydrofuran.

$\mathrm{mol}^{-1}$ and a dispersity of 1.35 were obtained in less than 3 h (run 6, Table 1). Ratio 3 or 4 was needed to get the highest molar masses and keep short polymerization times. They allow to increase the concentration of complexed monomer and, as a consequence, to increase the polymerization rate. It also induces a slight increase of chains distribution, observed for high molar masses, due to possible transfer reactions. ${ }^{43}$ Moreover, and as already reported for protected glycidol polymerization, ${ }^{46} i-\mathrm{Bu}_{3} \mathrm{Al}$ can be trapped by complexation with the oxygen of side group of PAGE units requiring a higher $\left[i-\mathrm{Bu}_{3} \mathrm{Al}\right] /\left[\mathrm{NOct}_{4} \mathrm{Br}\right]$ ratio in contrary to propylene oxide polymerization for example.

Lower true molar masses values, as compared to theoretical ones, were generally measured by SEC equipped with a viscosimeter detector. Higher ones were obtained with a refractive index detector calibrated with polystyrene (PS) standards showing an apparent difference of hydrodynamic volumes between PAGE and PS. According to all values, one can assume the formation of about one PAGE chain per initiator molecule and probably some residual transfer reactions for the high molar masses. The experimental values obtained increase linearly with conversion and with the initial molar ratio [AGE]/[Initiator]. These results are consistent with a living-like process with strongly limited transfer reactions, which is often the limiting point in conventional anionic polymerization of epoxides.

On the basis of our previous and present results, it may be concluded that AGE polymerization follows the mechanism presented in Scheme 1. It involves the formation of a NOct ${ }_{4}$ Br:triisobutylaluminum (1:1) complex of low basicity and the complexation of AGE by the trialkylaluminum allowing its strong activation toward the nucleophilic attack of the aluminate complex that yields rapid and controlled AGE polymerization.

The structure of PAGE was checked by ${ }^{1} \mathrm{H}$ and ${ }^{13} \mathrm{C}$ NMR analysis (see spectra in Supporting Information Figs. S1 and S2). The characteristic peak areas of pendant allyl group were observed at $5.87 \mathrm{ppm}(=\mathrm{CH})$ and $5.15-5.27 \mathrm{ppm}\left(=\mathrm{CH}_{2}\right)$. Absence of epoxide groups at 3.2 and 2.6-2.8 ppm was taken as a proof of the selectivity of the mechanism toward the 


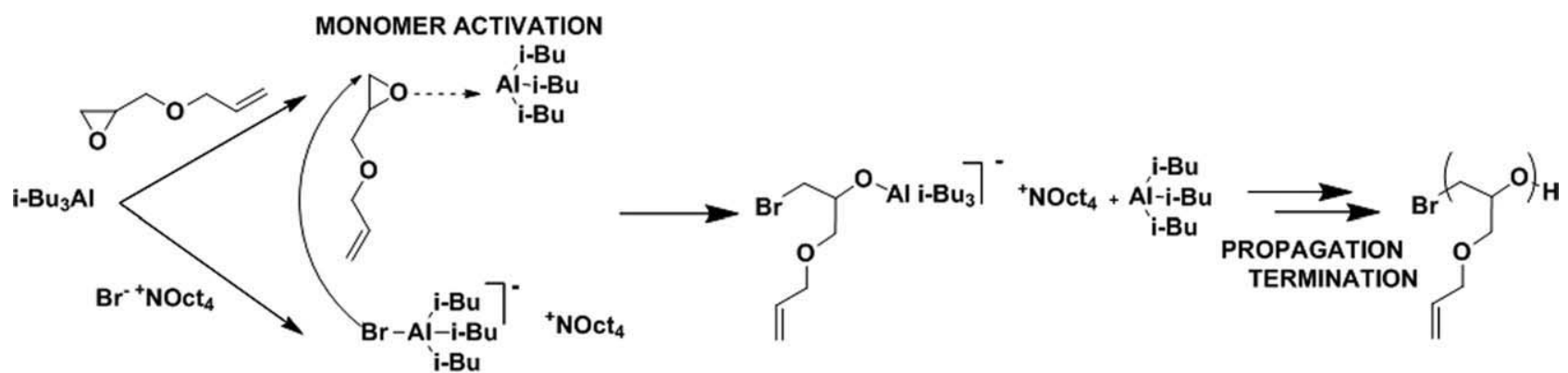

INITIATING COMPLEX FORMATION

SCHEME 1 Anionic ring opening polymerization mechanism via activation of allyl glycidyl ether.

epoxide ring opening. ${ }^{13} \mathrm{C}$ NMR spectrum also showed two single peaks at $117 \mathrm{ppm}\left(=\mathrm{CH}_{2}\right)$ and $135 \mathrm{ppm}(=\mathrm{CH})$. In addition and according to literature, data ${ }^{47}$ in-chain methylene and methine carbon signals were attributed to head-totail enchainments. The absence of head-to-head or tail-to-tail irregularities indicates an anionic coordinated type mechanism. The relative peak intensities of $\mathrm{CH}_{2}(77.0-77.6 \mathrm{ppm})$ resolved into $\mathrm{mm}, \mathrm{mr}$, and $\mathrm{rr}$ triads agrees with the formation of atactic PAGE. ${ }^{48}$

Synthesis of Poly(allyl glycidyl ether-co-epichlorohydrin) We have recently reported that controlled polymerization of ECH proceeds in similar experimental conditions using $\mathrm{NOct}_{4} \mathrm{Br}: i-\mathrm{Bu}_{3} \mathrm{Al}$ as initiating system. ${ }^{27} \mathrm{ECH}$ was chosen as a model monomer of other epoxides such as ethylene oxide, propylene oxide, or various glycidyl ethers and because its possible synthesis from glycerol. It also carries a reactive side group, which can be subject to a chemically post-modification giving especially poly(glycidyl azide) used as precursor for energetic polyurethanes. ${ }^{17}$ The copolymerization of AGE with ECH was investigated and results collected in Table 2 . As confirmed both by gravimetry and copolymer composition, quantitative conversion of the two monomers was achieved in short time $\left(<1 \mathrm{~h} 30 \mathrm{~min}\right.$ at $20^{\circ} \mathrm{C}$ in toluene) for $\left[i-\mathrm{Bu}_{3} \mathrm{Al}\right] /\left[\mathrm{NOct}_{4} \mathrm{Br}\right]$ ratios from 2 to 3 . P(AGE-co-ECH) copolymers (see Supporting Information Fig. S3 for ${ }^{1} \mathrm{H}$ NMR) of low dispersity with molar masses (apparent SEC values) increasing almost linearly with the ratio [monomers]/[initiator] were obtained.

Information on the distribution of AGE and ECH monomer units in the copolymers was gained by determining the comonomer reactivity ratios using the Kelen/Tüdos method. ${ }^{49}$ Several experiments were carried out at various comonomer feeds, and all copolymerizations were stopped at low conversion (less than 10\%). Reactivity ratios were found to be $r_{\mathrm{AGE}}$ $=k_{\mathrm{AGEAGE}} / k_{\mathrm{AGEECH}}=1.4$ and $r_{\mathrm{ECH}}=k_{\mathrm{ECHECH}} / k_{\mathrm{ECHAGE}}=$ 6.6. This indicates a small tendency to form gradient-like copolymers with a preferred ECH incorporation in the early stages of the reaction. This was further confirmed by monitoring the comonomer composition feed as a function of conversion, Figure 1. A 50:50 molar comonomer feed yields, at $10 \%$ conversion, a copolymer composed of $20 \%$ of AGE units, and $80 \%$ of ECH units, in agreement with a gradient structure.

\section{Synthesis of (Co)polyethers with Ethylene Carbonate Side Groups}

Transformation of allylic side groups of PAGE and P(AGE-co$\mathrm{ECH})$ into five-membered ethylene carbonate groups was achieved via epoxidation of the allylic unsaturation with

TABLE 2 Copolymerization of Allyl Glycidyl Ether and Epichlorohydrin Initiated by $\mathrm{NOct}_{4} \mathrm{Br} / \mathrm{i}-\mathrm{Bu}_{3} \mathrm{Al}$

\begin{tabular}{|c|c|c|c|c|c|c|c|c|}
\hline \multirow[b]{2}{*}{ Run } & \multicolumn{2}{|c|}{$\begin{array}{l}\text { Initial } \\
\text { Comonomer } \\
\text { Feed (mol \%) }\end{array}$} & \multicolumn{2}{|c|}{$\begin{array}{l}\text { Copolymer } \\
\text { Composition } \\
(\text { mol \% })^{b}\end{array}$} & \multirow[b]{2}{*}[i-\mathrm{Bu}_{3}\mathrm{Al}]{$/[\mathrm{I}]$} & \multirow{2}{*}{$\begin{array}{c}\bar{M}_{\mathrm{nth}} \\
\left(\mathrm{g} \mathrm{mol}^{-1}\right)\end{array}$} & \multirow{2}{*}{$\begin{array}{l}\bar{M}_{\text {nexp }}{ }^{\mathrm{c}} \\
\left(\mathrm{g} \mathrm{mol}{ }^{-1}\right)\end{array}$} & \multirow[b]{2}{*}{$\frac{\bar{M}_{\mathrm{w}}}{\bar{M}_{\mathrm{n}}}$} \\
\hline & AGE & $\mathrm{ECH}$ & AGE & $\mathrm{ECH}$ & & & & \\
\hline 1 & 71 & 29 & 65 & 35 & 2 & 2,000 & 2,800 & 1.13 \\
\hline 2 & 45 & 55 & 41 & 59 & 2 & 2,000 & 3,000 & 1.10 \\
\hline 3 & 21 & 79 & 18 & 82 & 2 & 2,000 & 3,000 & 1.08 \\
\hline 4 & 9 & 91 & 7 & 93 & 2 & 2,000 & 3,300 & 1.09 \\
\hline 5 & 45 & 55 & 42 & 58 & 2 & 5,000 & 7,500 & 1.10 \\
\hline 6 & 45 & 55 & 42 & 58 & 2 & 10,000 & 14,300 & 1.07 \\
\hline 7 & 45 & 55 & 42 & 58 & 3 & 25,000 & 28,800 & 1.06 \\
\hline
\end{tabular}




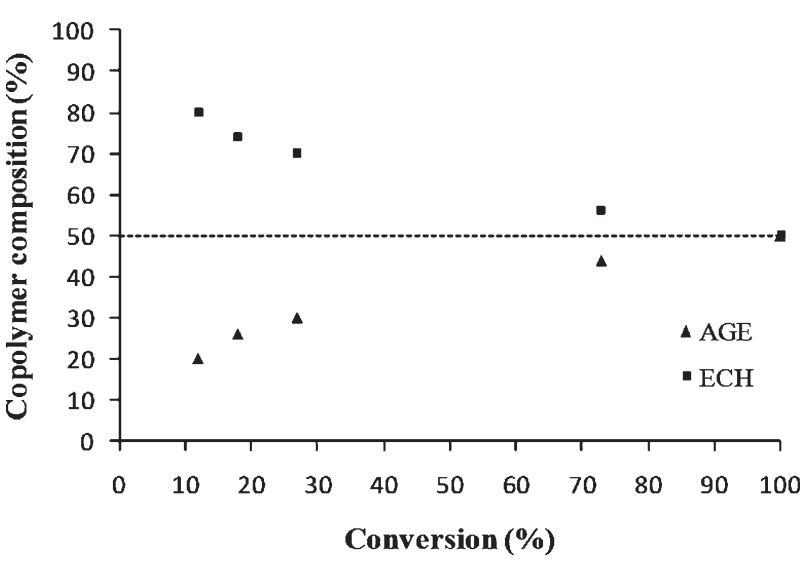

FIGURE 1 Evolution of the allyl glycidyl ether and ECH copolymer units composition with conversion (AGE/ECH $(\mathrm{mol} \%)=$ $50 / 50$, toluene, $T=25{ }^{\circ} \mathrm{C},\left[i-\mathrm{Bu}_{3} \mathrm{Al}\right] /\left[\mathrm{NOct}_{4} \mathrm{Br}\right]=2,[\mathrm{AGE}+\mathrm{ECH}]$ $=1.5 \mathrm{~mol} \mathrm{~L}^{-1}, 100 \%$ conversion $=45 \mathrm{~min}$ ).

meta-chloroperbenzoic acid and carbonation of the epoxide with $\mathrm{CO}_{2}$ as shown Scheme 2.

Epoxidation of the (co)polymers was carried out in dichloromethane with 2.5 molar excess of $m C P B A$ at room temperature. ${ }^{1} \mathrm{H}$ NMR spectrum of an epoxidized copolymer P(AGEeco-ECH) is shown Figure 2. A total disappearance of the characteristic peaks of the allylic protons at $5.87 \mathrm{ppm}$ and 5.15-5.27 ppm completely disappeared and the presence of three new peaks corresponding to epoxide protons at 2.98 ppm, 2.43 and 2.62 ppm support quantitative epoxidation of AGE units. Carbonatation was then carried out in DMF at 80 ${ }^{\circ} \mathrm{C}$ under 1 bar of $\mathrm{CO}_{2}$ for $10 \mathrm{~h}$. The ${ }^{1} \mathrm{H}$ NMR spectrum of the carbonated copolymer P(AGEc-Co-ECH) is shown Figure 3. It confirms the quantitative disappearance of the epoxide group and the formation of new signals at $4.83 \mathrm{ppm}$ and between 4.39 and $4.50 \mathrm{ppm}$ attributed to the ethylene carbonate group. This was further confirmed by the presence of a carbonyl signal at $155 \mathrm{ppm}$ in ${ }^{13} \mathrm{C}$ NMR.

\section{Polyurethane Synthesis}

Five members cyclic carbonate groups were reported to react with primary amines to form hydroxyurethane group $^{30-37}$ as illustrated in Scheme 3 for the present system. Synthesis of polyurethane networks by reaction of P(AGEc$\mathrm{co}-\mathrm{ECH})$ with IPDA was investigated. Results are presented Table 3.

The number of carbonated groups per chain corresponds to the number of allyl groups as reactions were quantitative. The glass transition temperatures $\left(T_{\mathrm{g}}\right)$ before crosslinking, measured by DSC, were given by the first heating run. During this run, an exothermic peak characteristic of the crosslinking reaction was observed. The $T_{\mathrm{g}}$ after crosslinking was determined during the second heating run. The absence of the exothermic peak also confirmed the end of the cyclic carbonate-amine reaction. As shown in Table 3, various copolymer compositions were prepared. As expected, $T_{\mathrm{g}}$ after crosslinking were shown to be higher than $T_{\mathrm{g}}$ before reaction. The polyurethane with the higher $T_{\mathrm{g}}\left(90^{\circ} \mathrm{C}\right)$ corresponds to the copolymer bearing the higher number of cyclic carbonate functions in agreement with a highly crosslinked network, all materials being nonsoluble.

Using IPDA and polyethers with pendant cyclic ethylene carbonate groups, crosslinked polyurethanes with $T_{\mathrm{g}}$ between -24 and $90{ }^{\circ} \mathrm{C}$ were obtained. The formation of such materials was then characterized by infrared spectroscopy (Fig. 4). Spectra of $\mathrm{P}$ (AGEc-Co-ECH) showed absorption bands at $1795 \mathrm{~cm}^{-1}$ for cyclic carbonate carbonyl function. The formation of polyurethanes was followed by the decrease and disappearance of this peak $\left(1795 \mathrm{~cm}^{-1}\right)$ on spectrum (b)

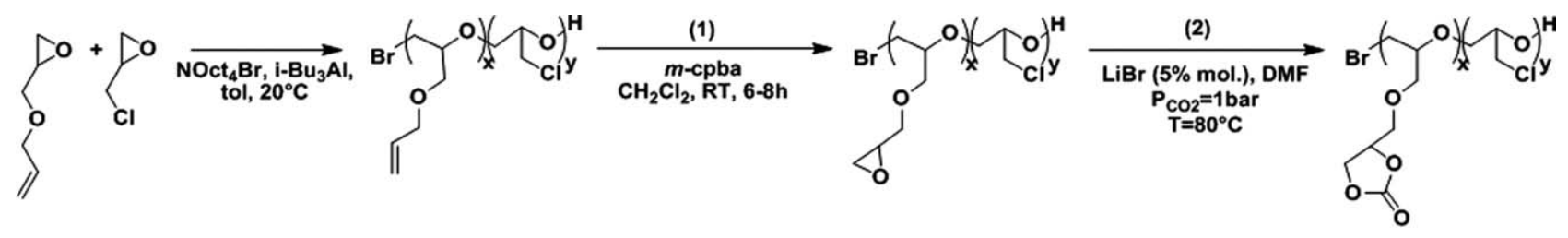

SCHEME 2 Epoxidation of P(AGE-co-ECH) followed by carbonatation to yield polyethers with ethylene carbonate side groups.

FIGURE $2{ }^{1} \mathrm{H}$ NMR spectrum in $\mathrm{CDCl}_{3}$ of epoxidized poly(allylglycidyl ether-co-epichlorohydrin) $\mathrm{P}(\mathrm{AGEe}-\mathrm{Co}-\mathrm{ECH})$ (initial AGE/ECH $=45 / 55 \mathrm{~mol} \%$, run 6 , Table 2 ).

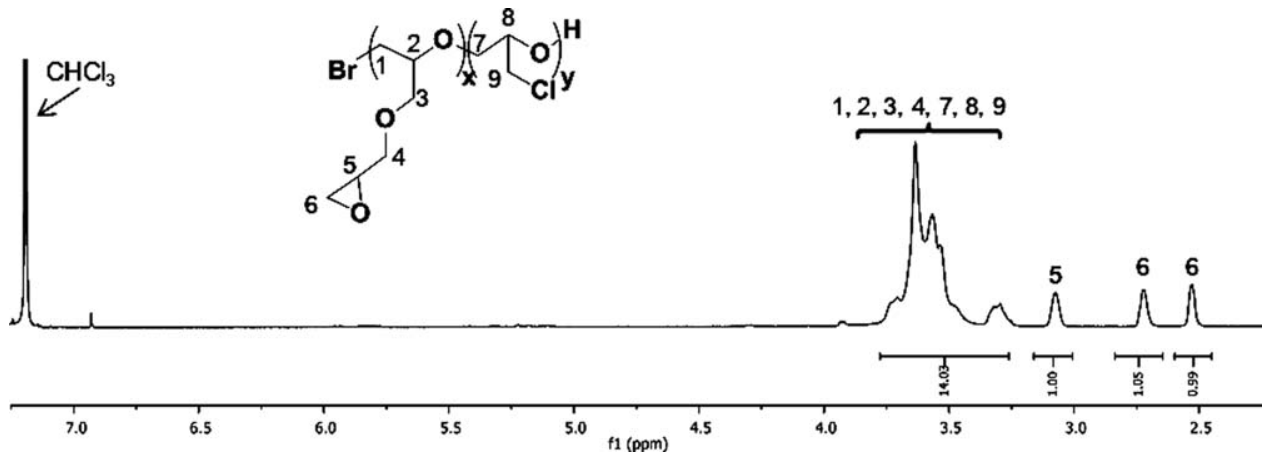




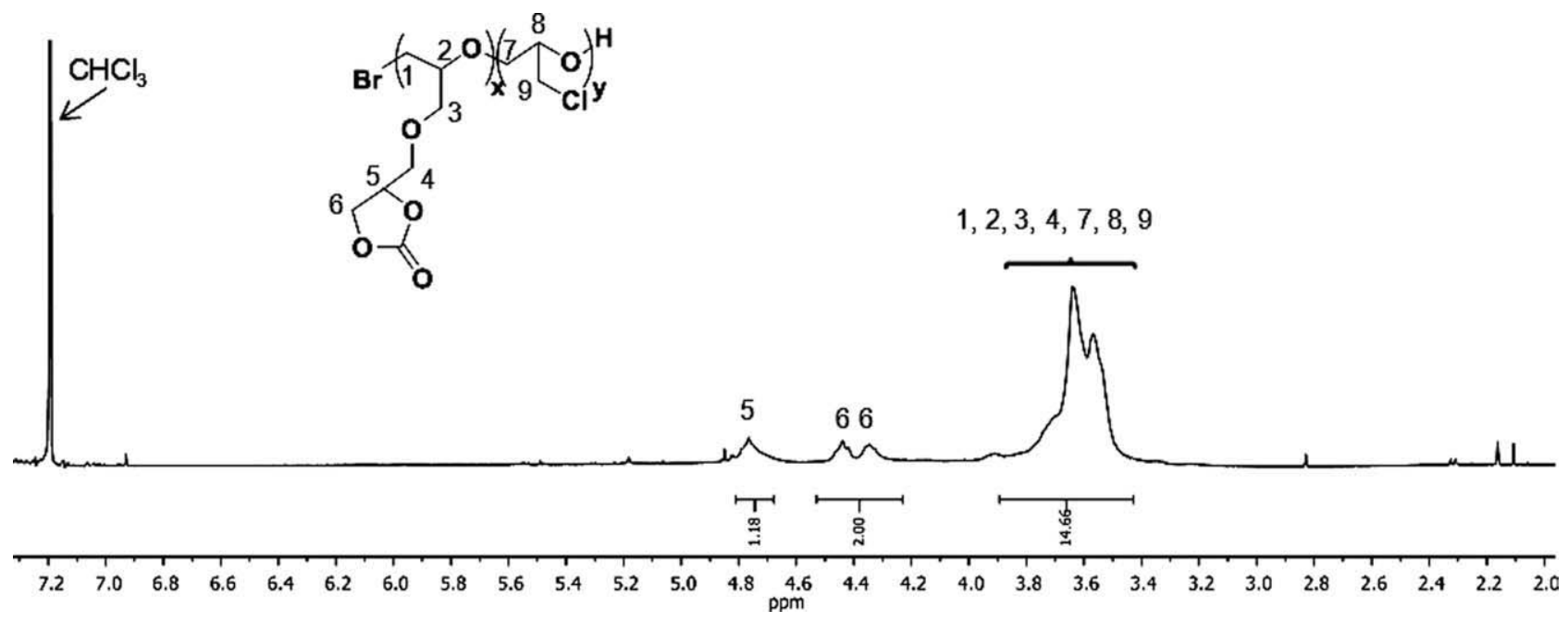

FIGURE $3{ }^{1} \mathrm{H}$ NMR spectrum in $\mathrm{CDCl}_{3}$ of carbonated poly(allylglycidyl ether-co-epichlorohydrin) $\mathrm{P}(\mathrm{AGEc}-\mathrm{Co}$-ECH) (initial AGE/ECH $=45 / 55 \mathrm{~mol} \%$, run 6 , Table 2).

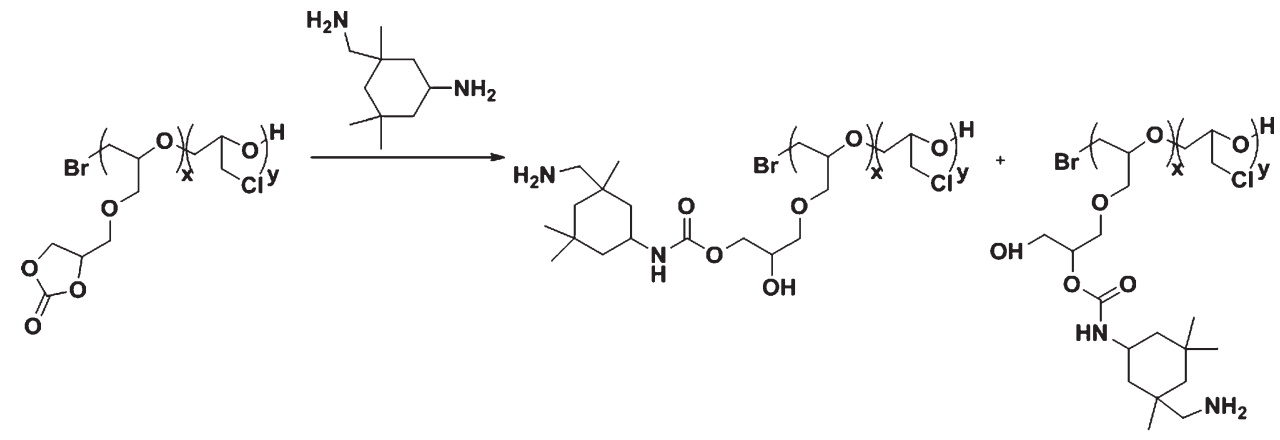

SCHEME 3 Formation of hydroxyurethane by reaction of ethylene carbonate group of $\mathrm{P}(\mathrm{AGEc}-$ co-ECH) with isophorone diamine. and the appearance of peaks characteristic of the urethane function, the carbonyl at $1710 \mathrm{~cm}^{-1}$ and amide at 1650 $\mathrm{cm}^{-1}$. As complementary information, the reaction between polyepichlorohydrin and IPDA gives no reaction. A particular focus on properties of polyhydroxyurethane materials based on various polyethers will be the object of further discussion.

\section{CONCLUSIONS}

A series of well-defined PAGE were prepared via anionic polymerization using $\mathrm{NOct}_{4} \mathrm{Br}$ as organic initiator and trii- sobutylaluminum as coinitiator and activator. This approach enables the formation of high molar mass polyethers up to $70,000 \mathrm{~g} \mathrm{~mol}^{-1}$ with a low dispersity in a few hours at room temperature. It allows the preparation of copolyethers based on allyl glycidyl ether and $\mathrm{ECH}$, both monomers potentially coming from the glycerol chemistry. Post-chemical modifications applied to the side double bonds afforded epoxidized and cyclocarbonated polyethers by a consecutive addition of peracide and $\mathrm{CO}_{2}$. The formation of polyurethane materials via a nonisocyanate route was taken as a final proof for the reactivity of

TABLE 3 Polyurethane Network Synthesis from Carbonated Poly(allyl glycidyl ether-co-epichlorohydrin) and Isophorone Diamine

\begin{tabular}{|c|c|c|c|c|c|c|}
\hline \multirow[b]{2}{*}{ Run } & \multicolumn{2}{|c|}{$\%$ (mol) exp. $^{a}$} & \multirow[b]{2}{*}{$\mathrm{N}_{\mathrm{CO} / \text { chain }^{\mathrm{b}}}$} & \multirow[b]{2}{*}{$\bar{M}_{\text {nexp }}\left(\mathrm{g} \mathrm{mol}^{-1}\right)$} & \multirow[b]{2}{*}{$T_{\mathrm{g}}\left({ }^{\circ} \mathrm{C}\right)$ before Crosslinking } & \multirow[b]{2}{*}{$T_{\mathrm{g}}\left({ }^{\circ} \mathrm{C}\right)$ after Crosslinking } \\
\hline & AGEc & $\mathrm{ECH}$ & & & & \\
\hline 1 & 65 & 35 & 13.1 & 2,800 & -36 & 90 \\
\hline 2 & 41 & 59 & 8.8 & 3,000 & -45 & 66 \\
\hline 3 & 18 & 82 & 4.4 & 3,000 & -42 & 40 \\
\hline 4 & 7 & 93 & 2.0 & 3,300 & -40 & -24 \\
\hline
\end{tabular}



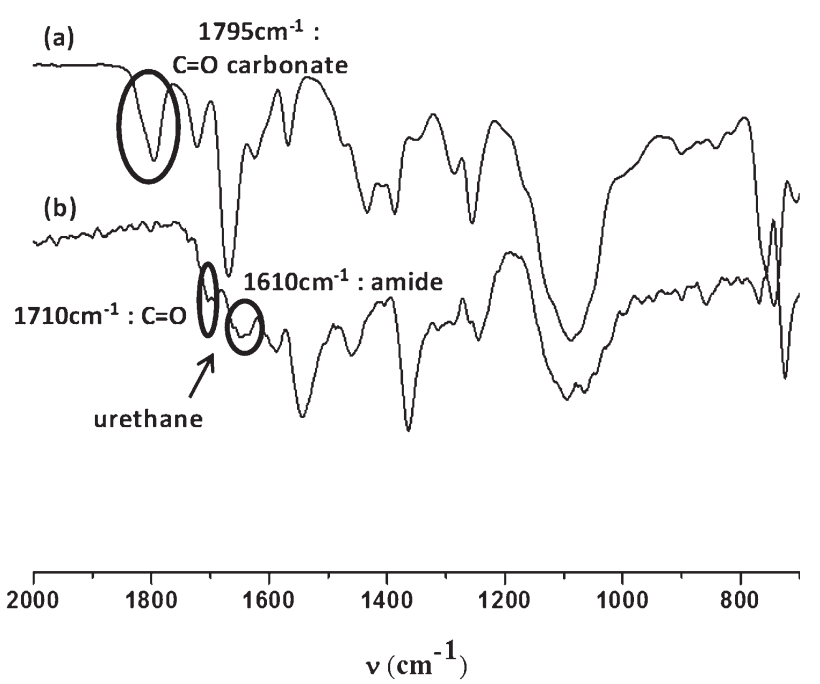

FIGURE 4 FTIR spectra of carbonated poly(allyl glycidyl etherco-epichlorohydrin) (a) and polyurethane (b) after its reaction with isophorone diamine $\left(T=80^{\circ} \mathrm{C}\right.$, time $\left.=3 \mathrm{~h}\right)$.

polyethers bearing pendant five-membered ethylene cyclic carbonates.

\section{REFERENCES AND NOTES}

1 Chattopadhyay, D. K.; Raju, K. V. S. N. Prog Polym Sci 2007, 32, 352-418.

2 Ephraim, S.; Woodward, A. E.; Mesrobian, R. B. J Am Chem Soc 1958, 80, 1326-1328.

3 Eissen, M.; Metzger, J. O.; Schmidt, E.; Schneidewind, U. Angew Chem Int Ed 2002, 41, 414-436.

4 Raquez, J. M.; Deléglise, M.; Lacrampe, M. F.; Krawczak, P. Prog Polym Sci 2010, 35, 487-509.

5 Petrovic, Z. S. Polym Rev 2008, 48, 109-155.

6 Behr, A.; Gomes, J. P. Eur J Lipid Sci Technol 2009, 112, 31-50.

7 Galià, M.; de Espinosa, L. M.; Ronda, J. C.; Lligadas, G.; Cadiz, V. Eur J Lipid Sci Technol 2009, 112, 87-96.

8 Van der Steen, M.; Stevens, C. V. ChemSusChem 2009, 2, 692-713.

9 Lligadas, G.; Ronda, J. C.; Galia, M.; Biermann, U.; Metzger, J. O. J Polym Sci Part A: Polym Chem 2006, 44, 634-645.

10 Pagliaro, M.; Ciriminna, R.; Kimura, H.; Rossi, M.; Della Pina, C. Angew Chem Int Ed 2007, 46, 4434-4440.

11 Santacesaria, E.; Tesser, R.; Di Serio, M.; Casale, L.; Verde, D. Ind Eng Chem Res 2009, 49, 964-970.

12 Xie, H. Q.; Guo, J. S.; Yu, G. Q.; Zu, J. J Appl Polym Sci 2001, 80, 2446-2454.

13 Bell, B.; Briggs, J. R.; Campbell, R. M.; Chambers, S. M.; Gaarenstroom, P. D.; Hippler, J. G.; Hook, B. D.; Kearns, K.;
Kenney, J. M.; Kruper, W.; Schreck, D.; Therlault, C. N.; Wolfe, C. P. Clean: Soil Air Water 2008, 36, 657-661.

14 (a) Krafft, P.; Gilbeau, P.; Balthasart, D. FR2913683, 2008; (b) Kubicek, P.; Sladek, P.; Buricova, I., US0082601, 2009.

15 (a) Brochu, S.; Ampleman, G. Macromolecules 1996, 29, 5539-5545; (b) Callau, L.; Reina, J. A.; Mantecon, A. J Polym Sci Part A: Polym Chem 2002, 40, 3893-3908.

16 Jackson, M. B.; Vickers, L. J. React Polym Ion Exch Sorbents 1988, 8, 211-220.

17 (a) Frankel, M. B.; Grant, L. R.; Flanagan, J. E. J Propul Power 1992, 8, 560-563; (b) Mohan, Y. M.; Raju, M. P.; Raju, K. M. J Appl Polym Sci 2004, 93, 2157-2163.

18 Koyama, Y.; Umehara, M.; Mizuno, A.; Itaba, M.; Yasukouchi, T.; Natsume, K.; Suginaka, A.; Watanabe, K. Bioconjugate Chem 1996, 7, 298-301.

19 Yoshikawa, K.; Yoshikawa, Y.; Koyama, Y.; Kanbe, T. J Am Chem Soc 1997, 119, 6473-6477.

20 Hrubý, M.; Konak, C.; Ulbrich, K. J Appl Polym Sci 2005, 95, 201-211.

21 Giguère, G.; Zhu, X. X. Biomacromolecules 11, 201-206.

22 He, F.; Wang, Y. P.; Liu, G.; Jia, H. L.; Feng, J.; Zhuo, R. X. Polymer 2008, 49, 1185-1190.

23 Calo, V.; Nacci, A.; Monopoli, A.; Fanizzi, A. Org Lett 2002, 4, 2561-2563.

24 Erberich, M.; Keul, H.; Moller, M. Macromolecules 2007, 40, 3070-3079.

25 Aukaszczyk, J.; Jaszcz, K. Macromol Chem Phys 2002, 203, 301-308.

26 Stolarzewicz, A.; Neugebauer, D. Macromol Chem Phys 1999, 200, 2467-2470.

27 Carlotti, S.; Labbé, A.; Rejsek, V.; Doutaz, S.; Gervais, M.; Deffieux, A. Macromolecules 2008, 41, 7058-7062.

28 (a) Kihara, N.; Hara, N.; Endo, T. J Org Chem 1993, 58, 6198-6202; (b) Sakai, T.; Kihara, N.; Endo, T. Macromolecules 1995, 28, 4701-4706.

29 (a) Ochiai, B.; Endo, T. J Polym Sci Part A: Polym Chem 2007, 45, 5673-5678; (b) Ochiai, B.; Iwamoto, T.; Miyagawa, T.; Nagai, D.; Endo, T. J Polym Sci Part A: Polym Chem 2004, 42, 3812-3817.

30 Boyer, A.; Cloutet, E.; Tassaing, T., Gadenne, B.; Alfos, C.; Cramail, H. Green Chem 2010, 12, 2205-2213.

31 Rokicki, G.; Piotrowska, A. Polymer 2002, 43, 2927-2935.

32 Steblyanko, A.; Choi, W.; Sanda, F.; Endo, T. J Polym Sci Part A: Polym Chem 2000, 38, 2375-2380.

33 (a) Tomita, H.; Sanda, F.; Endo, T. J Polym Sci Part A: Polym Chem 2001, 39, 162-168; (b) Tomita, H.; Sanda, F.; Endo, T. J Polym Sci Part A: Polym Chem 2001, 39, 851-859.

34 Tomita, H.; Sanda, F.; Endo, T. J Polym Sci Part A: Polym Chem 2001, 39, 3678-3685.

35 Kihara, N.; Kushida, Y.; Endo, T. J Polym Sci Part A: Polym Chem 1996, 34, 2173-2179. 
36 He, Y.; Keul, H.; Möller, M. React Funct Polym 2011, 71, 175-186.

37 Tamami, B.; Sohn, S.; Wilkes, G. L. J Appl Polym Sci 2004, 92, 883-891.

38 Javni, I.; Doo, P. H.; Petrovic, Z. S. J Appl Polym Sci 2008, 108, 3867-3875.

39 Neffgen, S.; Keul, H.; Höcker, H. Macromol Rapid Commun 1996, 17, 373-382.

40 Neffgen, S.; Keul, H.; Höcker, H. Macromolecules 1997, 30, 1289-1297.

41 Prömpers, G.; Keul, H.; Höcker, H. Green Chem 2006, 8, 467-478.

42 Billouard, C.; Carlotti, S.; Desbois, P.; Deffieux, A. Macromolecules 2004, 37, 4038-4043.
43 Labbe, A.; Carlotti, S.; Billouard, C.; Desbois, P.; Deffieux, A. Macromolecules 2007, 40, 7842-7847.

44 Rejsek, V.; Sauvanier, D.; Billouard, C.; Desbois, P.; Deffieux, A.; Carlotti, S. Macromolecules 2007, 40, 6510-6514.

45 Labbé, A.; Carlotti, S.; Deffieux, A.; Hirao, A. Macromol Symp 2007, 249-250, 392-397.

46 Gervais, M.; Brocas, A-L.; Cendejas, G.; Deffieux, A.; Carlotti, S. Macromolecules 2010, 43, 1778-1784.

47 Antelmann, B.; Chislom, H. C.; lyer, S. S.; Huffman, J. C.; Navarro-Llobet, D.; Pagel, M.; Simonsick, W. J.; Zhong, W. Macromolecules 2001, 34, 3159-3175.

48 Chisholm, M. H.; Navarro-Llobet, D. Macromolecules 2002, 35, 2389-2392.

49 Kelen, T.; Tüdos, F. J Macromol Sci Chem 1975, A9, 1-27. 